\title{
Fungal diversity and mycotoxin contamination in dried fish products in Zhanjiang market, China
}

\author{
Yijia Deng $^{\mathrm{a}}$, Yaling Wang ${ }^{\mathrm{a}, *}$, Qi Deng ${ }^{\mathrm{a}, * *}$, Lijun Sun ${ }^{\mathrm{a},{ }^{* * *},}$, Rundong Wang ${ }^{\mathrm{b}}$, Lin Ye ${ }^{\mathrm{a}}$, Sen Tao ${ }^{\mathrm{a}}$, \\ Jianmeng Liao $^{c}$, Ravi Gooneratne ${ }^{\mathrm{d}}$ \\ ${ }^{a}$ College of Food Science and Technology, Guangdong Ocean University, Guangdong Provincial Key Laboratory of Aquatic Product Processing and Safety, Guangdong \\ Provincial Engineering Technology Research Center of Marine Food, Key Laboratory of Advanced Processing of Aquatic Products of Guangdong Higher Education \\ Institution, Zhanjiang, 524088, China \\ ${ }^{\mathrm{b}}$ School of Chemistry and Chemical Engineering, Lingnan Normal University, Zhanjiang, 524048, China \\ ${ }^{\mathrm{c}}$ Zhanjiang Institute for Food and Drug Control, Zhanjiang, 524022, China \\ ${ }^{\mathrm{d}}$ Department of Wine, Food and Molecular Biosciences, Faculty of Agriculture and Life Sciences, Lincoln University, P.O. Box 85084, Lincoln, 7647, New Zealand
}

\section{A R T I C L E I N F O}

\section{Keywords:}

Dried fish

Fungi contamination

Molecular identification

Mycotoxin

Aflatoxin $\mathrm{B}_{1}$

\begin{abstract}
A B S T R A C T
Dried fish are important dietary protein and income sources in Zhanjiang, China. Mycotoxins produced by pathogenic fungi that contaminate fish during processing can cause considerable hazard to consumer health. This study reports fungal diversity, total fungal counts and mycotoxin contamination of dried fish sold at the seafood market in Zhanjiang. Seven dried fish products (Hemibarbus maculatus, Pseudosciaena crocea, Lutjanus erythopterus, Thunnus thynnus, Scomberomorus niphonius, Eleutheronema tetradactylum, Trichiurus lepturus, $\mathrm{n}=10$ ) from seven retailers were analyzed for contaminated fungal species, occurrence frequency and residues analysis of four mycotoxins. Using potato dextrose agar (PDA) plate purification, morphology observation, internal transcribed spacer (ITS) sequence analysis, 25 fungal strains representing 12 genera from dried fish were systematically isolated and identified. Three dominant genera in dried fish were Fusarium sp. (80.4\%), Penicillium sp. (70.7\%) and Aspergillus sp.(63.9\%). Other fungal genera were Neoscytalidium sp.(38.1\%), Cutaneotrichosporon sp. (38.1\%), Trichoderma sp.(20.3\%), Naganishia sp.(15.3\%), Kodamaea sp. (10.8\%), Phialemoniopsis sp.(9.2\%), Nigrospora sp.(7.3\%), Ceriporia sp.(6.3\%), Phellinus sp.(4.5\%). Aspergillus flavus contamination was the higher and ranged from $1.10 \times 10^{3}$ to $2.40 \times 10^{4} \mathrm{cfu} / \mathrm{g}$. The mean fungal contamination of other fungal species in dried fish ranged from $1.07 \times 10^{2}$ to $4.58 \times 10^{4} \mathrm{cfu} / \mathrm{g}$. The total fungal counts of Fusarium sp. ranged from $1.09 \times 10^{2}$ to $2.11 \times 10^{4} \mathrm{cfu} / \mathrm{g}$, but the occurrence frequency is relatively high. Liquid chromatography-tandem mass spectrometry (LC-MS/MS) analyses showed that mycotoxin residues were present in 12 out of the 25 dried fish tested. Aflatoxin $\mathrm{B}_{1}\left(\mathrm{AFB}_{1}\right)$ was the most frequently detected and the concentration ranged from 0.03 to $3.52 \mu \mathrm{g} / \mathrm{kg}$. T-2 toxin (T-2), ochratoxin A (OTA), and deoxynivalenol (DON) concentrations ranged from 0.21 to $1.53,0.03-2.21$ and $0.71 \mu \mathrm{g} / \mathrm{kg}$ respectively. High occurrence of fungal populations and mycotoxins in dried fish sold in the Zhanjiang market pose a potential threat to consumer health. It is recommended that in future, advanced processing methods and controlled storage condition need to be used to minimize and if possible eliminate fungal contamination during dried fish processing.
\end{abstract}

\section{Introduction}

Fish is one part of the important animal protein sources in the tropics and is exceptionally rich in calcium (Ca) and phosphorus $(\mathrm{P})$ and $\beta$ vitamins (Oluwaniyi \&;Dosumu, 2009). Consumption of fish and fish products is popular especially in coastal areas. However, fresh fish is perishable and are hence processed to improve shelf life. Currently, chilling, freezing, salting, canning, drying and smoking, are the most commonly used techniques used for effective preservation (Kumolu-Johnson, Aladetohun \& Dimele, 2010). Among these drying is the most

\footnotetext{
* Corresponding author.

$* *$ Corresponding author.

$* * *$ Corresponding author.

E-mail addresses: gdouwang@163.com (Y. Wang), dengqi1024@163.com (Q. Deng), dfsun01@163.com (L. Sun).
} 
popular. In India, about $17 \%$ of the total seafood catch is dried (Jeya, Vijayalakshmi, \& Jeyasekaran, 2003). In the southern China, especially in Zhanjiang (Fig. 1), the annual fresh fish production is $>100,000 \mathrm{~kg}$. Salted-fish drying is the traditional method for seafood preservation in coastal areas and is very popular with the consumers. However, drying fish does not completely inhibit microbial growth. The microbial presence lowers the quality of fish products.

In most instances, fresh seawater fish are salted and dried in the sun in preference to professional food processing industry. This can lead to food safety issues because the drying conditions cannot be easily regulated with some fishermen prefer to dry them on streets or in open balconies of houses as practiced in many Asian and African countries (Akwuobu, Antiev, \& Ofukwu, 2019; Gonkowski, Obremski, Makowska, \& Rytel, 2018; Sam, Jeyasanta, \& Edward, 2015). The quality of dry fish prepared outdoor by open sun drying is compromised by the bacterial, fungal, insect, and rodent contamination, and also by the unhygienic handling, and poor quality of salt and water used for fish processing (Sugumar, Jawahar, \& Jayachandran, 1995). Several studies have reported the decline in dried fish quality of affected by fungal growth (Hassan, Hassan, El Shafei, El Ahl, \& El-Dayem, 2011; Begum, Akter, Ahmed, \& Md, 2011; Adeyeyea, 2016; Sa'adatu, Nura, \& Muhammad, 2019). Thus, microbial contamination affects the meat quality by alteration of flavour, texture and loss of nutrients and also food safety problems (Singapurwa, Suprapta, Gunam, \& Khalimi, 2018), all of which can result in a huge economic loss to the industry.

According to the reports, a range of fungal species isolated from dried fish can accelerate the deterioration of dried fish (Atapattu, Sama,

Ajeewa, 1990; Zachariasova et al., 2014; Dègnon, Atrevy, Adjou, Ahoussi, \& Soumanou, 2018). Common fungal genera that contaminate dried fish were Aspergillus sp., Penicillium sp., Rhizopus sp., and Fusarium sp. (Olajuyigbe et al., 2014; Jimoh et al., 2014). Ayeloja, George, Jimoh, Shittu, and Abdulsalami (2018) reported the growth of A. flavus, F. oxysporum, Ceotrichium albidium, Penicillium sp, and Trrichoderma sp. in smoked fish sold in Ibadan. Fagbohun and Lawal investigated isolated A. flavus and Penicillium sp. (both about $27 \%$ each) $>$ Rhizopus sp., and Fusarium sp. fungal species in smoked dried fish products in different markets in Nigeria. (Fagbohun \& Lawal, 2015). In Kenya's Gucha South district market, A. niger (17.57\%) and Rhizopus sp. (29.73\%) were the highest fungal species recovered from sun dried fish (Nyamwaka, Nyamache, \& Maingi, 2017). To our knowledge, there are only a few reports on contaminated fungal species in dried fish in coastal areas of China. Therefore, the investigation of fungal diversity in dried fish provides an important data for risk assessment of dried seafood safety.

Mycotoxins are the secondary metabolites produced by various filamentous fungal species and the most common are aflatoxins (AFs),

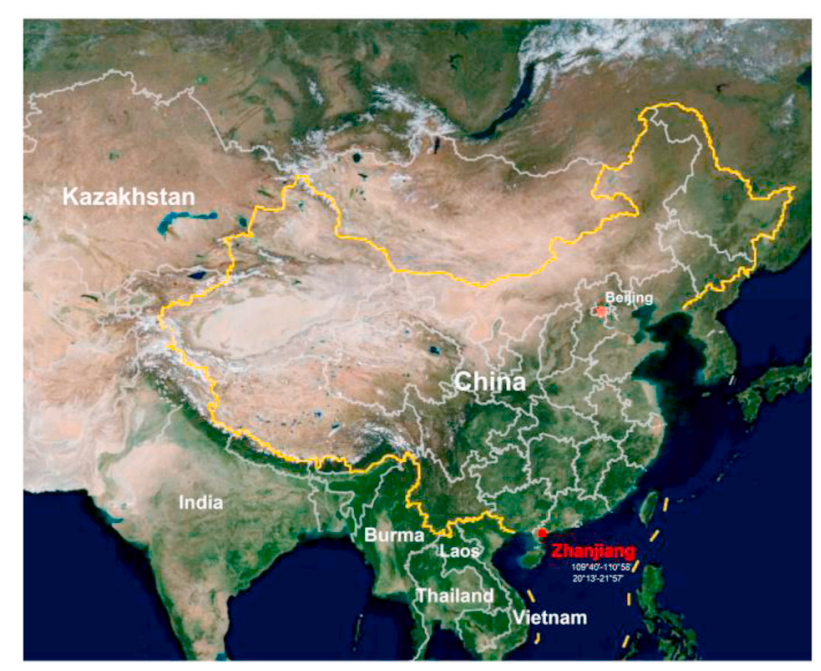

Fig. 1. Geographical location of Zhanjiang, China. ochratoxins (OTs), Fusarium mycotoxins (e.g. deoxynivalenol (DON), T2 toxin, zearalenone (ZEN)) and fumonisins (FBs) (Adekoya, Obadina, Phoku, Nwinyi, \& Njobeh, 2017; Zachariasova et al., 2014). Mycotoxin concentrations vary depending on season, substrate and storage conditions. They are generally stable and difficult to eliminate from the food chain (Omotayo, Omotayo, Mwanza, \& Babalola, 2019). Due to the inadequate control of temperature and humidity during storage, dried fish products are highly prone to mycotoxin contamination. Much mycotoxin research have been conducted in some tropical regions in Africa (Akinyem et al., 2011; Fagbohun \& Lawal, 2015) and India (Sam et al., 2015), Fagbohun \& Lawal (2015) detected 2.73-4.03 $\mu \mathrm{g} / \mathrm{kg} \mathrm{AFB}$ and $2.01-3.53 \mu \mathrm{g} / \mathrm{kg} \mathrm{AFG}$ residues in 50 smoked dried fish samples randomly purchased from the main market of Ado-Ekiti, Nigeria. Gonkowski et al. (2018) reported 100\% ZEN contamination of sun-dried fish in Zambia. Thus humans could be exposed to multiple potentially hazardous mycotoxins when dried fish products are consumed. Tolosa, Barba, Font, and Ferrer (2019) have found small amounts of fusarenon-X and enniatin B were residued in smoked fish during processing.

In China, Sun et al. (2015) reported that 3.5-317.3 $\mu \mathrm{g} / \mathrm{kg}$ of ZEN and $1.9 \mu \mathrm{g} / \mathrm{kg}$ OTA residues in dried seafood products sold in Shanghai. Zhanjiang is located in the southern part of China. It is usually hot/warm and humid which is ideal for fungal growth and mycotoxin production. but no studies have been carried out in relation to fungal and mycotoxin contamination in dried fish products obtained from southern China markets. This study was conducted to investigate the diversity, occurrence frequency of contaminated fungi species and analyse quantificationally of mycotoxin concentration of dried fish products sold in seafood market in Zhanjiang.

\section{Materials and methods}

\subsection{Sampling collection and preparation}

A total of 70 samples including seven dried fish species (Hemibarbus maculatus, Pseudosciaena crocea, Lutjanus erythopterus, Thunnus thynnus, Scomberomorus niphonius, Eleutheronema tetradactylum, Trichiurus lepturus, $\mathrm{n}=10$ ) were randomly sampled from seafood markets in Zhanjiang, China. Dried fish products were transferred into individual polythene bags, sealed, labeled and transported to the Guangdong Ocean University microbiology laboratory in Zhanjiang. The samples were stored at ambient temperature until analysis.

\subsection{Mycological analysis}

The $25 \mathrm{~g}$ dried fish were cut into small cubes and homogenized with $225 \mathrm{~mL}$ of sterile distilled water. Following a ten-fold serial dilution, 1 $\mathrm{mL}$ diluent was spread on the Potato Dextrose Agar (PDA) medium with $40 \mu \mathrm{g} / \mathrm{mL}$ chloramphenicol. Different morphology, color, size of the colonies were enumerated $(\mathrm{cfu} / \mathrm{g}$ ) respectively after 5 days of incubation at $28{ }^{\circ} \mathrm{C}$.

\subsection{Fungal isolation and purification}

The $100 \mu \mathrm{L}$ of the above mentioned diluent (in section 2.2) of each sample was spread on sterile PDA medium and incubated at $28^{\circ} \mathrm{C}$ for 4 d. Morphologically distinct colonies were sub cultured on fresh media to obtain pure isolates and further maintained at $4{ }^{\circ} \mathrm{C}$ on PDA medium. After $4 \mathrm{~d}$ of incubation, different fungal species were distinguished through colony morphology, color, size and texture. Pure isolates were numbered and stored at $-20{ }^{\circ} \mathrm{C}$ for further identification.

\subsection{DNA extraction, polymerase chain reaction and sequencing}

Molecular identification was conducted on the basis of nucleotide sequence of DNA. The DNA of each fungus was extracted using a kit (Ezup Column Fungi Genomic DNA Purification Kit, Sangon Biotech Co., 
Ltd., China). The ribosomal rRNA gene was amplified using universal fungal primers: internal transcribed spacer 1 (ITS1: 50-TCC GTA GGT GAA CCT GCGG-30), and internal transcribed spacer 4 (ITS4: 50-TCC TCC GCT TAT TGA TAT GC-30). The PCR reaction mixture was prepared using EF-Taq as follows: $10 \times$ EF-Taq buffer $2.5 \mu \mathrm{L}, 10 \mathrm{mM}$ dNTP (T) $0.5 \mu \mathrm{L}$, each primer (10 pmol) $1.0 \mu \mathrm{L}$, Taq DNA polymerase $(0.6 \mathrm{U})$ $0.5 \mu \mathrm{L}$, DNA template $1.0 \mu \mathrm{L}$, double distilled water (up to $25 \mu \mathrm{L}$ ). PCR amplification was performed in a thermal cycler (LongGene Thermal Cycler, LongGene Scientific Instruments Co., Ltd., China) with the following cycling parameters: one cycle of denaturation at $95{ }^{\circ} \mathrm{C}$ for $15 \mathrm{~s}$ followed by 30 cycles of denaturation at $95{ }^{\circ} \mathrm{C}$ for $15 \mathrm{~s}$, annealing at $57{ }^{\circ} \mathrm{C}$ for $15 \mathrm{~s}$, extension at $72^{\circ} \mathrm{C}$ for $1 \mathrm{~min}$ and a final extension step at $72{ }^{\circ} \mathrm{C}$ for $5 \mathrm{~min}$. To evaluate the quality of the amplicons, $5 \mu \mathrm{L}$ PCR products were analyzed by electrophoresis in $1 \%$ standard agarose gel (using a DNA ladder). Gels were electrophoresed at $100 \mathrm{~V}$ for $30 \mathrm{~min}$ and photographed using a UV transilluminator and Gel Smart system software. Amplification products were sent to Sangon Biotech (Shanghai) Co., Ltd. for sequencing. The sequence was compared with other ITS rDNA gene sequences obtained from the NCBI GenBank database. The resulting alignment was loaded and analyzed with the phylogenetic analysis program MEGA version 7.0. The best model was estimated for each dataset considering the Bayesian information criterion (BIC) and the Akaike information criterion (AIC).

\subsection{Dried fish: mycotoxin analysis}

\subsubsection{Mycotoxin extraction}

Two gram of dried fish was added with $10 \mathrm{~mL}$ of acetonitrile/water (v: v, 85/15), homogenized (IKAT25, Staufen, Germany) for $1 \mathrm{~min}$ $(10,000 \mathrm{r} / \mathrm{min})$. The mixed solution was subjected to ultrasound assisted extraction (UAE) (PS-30 A, power: $180 \mathrm{~W}$, frequency: $40 \mathrm{kHz}$, Ruimi Instruments Co., Changzhou, China) for $60 \mathrm{~min}$ at $20^{\circ} \mathrm{C}$, then centrifuged at $4500 \times g$ for $10 \mathrm{~min}$. This extraction process was repeated twice and the supernatants were combined. The supernatants were mixed and subsequently evaporated to dryness using a gentle nitrogen stream at $50{ }^{\circ} \mathrm{C}$, then redissolved in $1 \mathrm{~mL}$ of methanol/water $(30 / 70, \mathrm{v} / \mathrm{v})$ with $0.1 \%$ formic acid. The solution was ultrasonically irradiated for $3 \mathrm{~min}$ and mixed by vortexing (XW-80 A, Haimen, China) for $1 \mathrm{~min}$. The solution was then filtered through a $0.22-\mu \mathrm{m}$ filter (diameter- $25 \mathrm{~mm}$, polyamide 6 , organic phase, Tianjin, China) and stored at $-20^{\circ} \mathrm{C}$ until LC-MS/MS analysis.

\subsection{2. $L C-M S / M S$ analysis}

Toxin analysis was performed on a Thermo Scientific Surveyor HPLC system that comprised a Surveyor MS Pump Plus, an on-line degasser, and a Surveyor Autosampler Plus coupled with a Thermo TSQ Quantum Access tandem mass spectrometer equipped with an electrospray ionization (ESI) source (Table 1).

(Massachusetts, USA). The separation was performed at $35^{\circ} \mathrm{C}$ using a Hypersil GOLD column $(5 \mu \mathrm{m}, 100 \mathrm{~mm} \times 2.1 \mathrm{~mm})$ (Thermo Scientific,

Table 1

Optimal precursor and product ions of analytes of the mycotoxins with the respective collision energy (eV) values used in MS/MS analysis.

\begin{tabular}{lllll}
\hline Toxin & $\begin{array}{l}\text { Precursor ion }(\mathrm{m} / \\
\mathrm{z})\end{array}$ & $\begin{array}{l}\text { Product ions }(\mathrm{m} / \\
\mathrm{z})\end{array}$ & $\mathrm{CE}^{\mathrm{b}}(\mathrm{eV})$ & $\begin{array}{l}\text { Retention time } \\
(\mathrm{min})\end{array}$ \\
\hline $\mathrm{AFB}_{1}$ & $313.0[\mathrm{M}+\mathrm{H}]^{+}$ & 213.0 & 44 & 5.90 \\
& & $241.0^{\mathrm{a}}$ & 36 & \\
$\mathrm{~T}-2$ & $484.3\left[\mathrm{M}+\mathrm{NH}_{4}\right]^{+}$ & $185.1^{\mathrm{a}}$ & 27 & 6.30 \\
& & 215.1 & 25 & \\
OTA & $402.0[\mathrm{M}-\mathrm{H}]^{+}$ & 238.1 & 27 & 4.91 \\
& & $358.1^{\mathrm{a}}$ & 15 & \\
DON & $295.0[\mathrm{M}-\mathrm{H}]^{+}$ & 203.1 & 16 & 5.25 \\
& & $249.1^{\mathrm{a}}$ & 12 & \\
\hline
\end{tabular}

\footnotetext{
a Quantitative ion.

b CE: collision energy.
}

CA, USA) with a flow rate of $0.25 \mathrm{~mL} / \mathrm{min}$. The injection volume was 5 $\mu \mathrm{L}$. The mobile phase consisted of methanol (A) and water containing 5 $\mathrm{mM}$ ammonium acetate $0.1 \%$ formic acid (B) with the gradient elution program as follows: $0 \mathrm{~min} 30 \% \mathrm{~A}, 3.0 \mathrm{~min} 90 \% \mathrm{~A}, 5 \mathrm{~min} 90 \% \mathrm{~A}$, from $5.1 \mathrm{~min}$ to $8 \mathrm{~min} 30 \% \mathrm{~A}$ and hold on for a further $2 \mathrm{~min}$ for reequilibration, giving a total run time of $10 \mathrm{~min}$.

MS/MS detection was carried out using a triple quadruple mass spectrometer, coupled with an electrospray ionization source operated in both positive (ESI+) mode (Shimadzu, Kyoto, Japan). The ionization source parameters were set as follows: spray voltage: $4500 \mathrm{~V}$; sheath gas pressure: $35 \mathrm{au}$; ion sweep gas pressure: $0 \mathrm{au}$; auxiliary gas pressure: 15 au; capillary temperature: $350{ }^{\circ} \mathrm{C}$; tube lens offset: $118 \mathrm{~V}$; skimmer offset: 0; collision energy: $1.5 \mathrm{eV}$; and collision pressure: 1.5 mTorr. Quantitation was performed in multiple reaction monitoring (MRM) mode and the conditions were optimized for each mycotoxin during infusion. Through optimization, the limit of detection (LOD) of $\mathrm{AFB}_{1}, \mathrm{~T}$ 2 , OTA and DON were $0.1,0.1,0.1$ and $1.0 \mu \mathrm{g} / \mathrm{kg}$, respectively, limit of quantification (LOQ) were $0.3,0.3,0.5,3.0 \mu \mathrm{g} / \mathrm{kg}$, respectively. The recovery of four mycotoxin in dried fish ranged from 90.1 to $103.8 \%$.

\subsection{Data analysis}

Sequences were further analyzed by BLAST from the National Center of Biotechnology Information (NCBI) website. The data were analyzed again by aligning the sequence though using MEGA version 7.0 program.

\section{Results and discussion}

\subsection{Isolation and diversity of contaminated fungi}

Twenty-five fungal isolates with different colony morphology were isolated from seven types of dried fish products (Fig. 2). Twenty-two isolated colonies were filamentous fungi and 3 colonies (ZJC23, ZJC24, ZJC25) showed a yeast-like morphology in PDA agar. By analysis, In the present study the contaminating fungal mycobiota form seven dried fish products was identified. Isolates from 12 fungal genera were identified. Three dominant genera were Aspergillus sp., Penicillium sp. and Fusarium sp. This finding is consistent with Nyamwaka, Nyamache, \& Maingi (2017) who reported that the most common fungal genera grew in sun dried fish sold in market. Aspergillus sp. is the most common fungus in dried fish reported by many research (Hassan et al., 2011; Olajuyigbe et al., 2014; Jimoh et al., 2014; Wogu \& Iyayi, 2011). Except common fungal genera, several uncommon fungal genera such as Neoscytalidium sp. Ceriporia sp., Nigrospora sp., Cutaneotrichosporon sp., Naganishia sp. and Phialemoniopsis sp. were isolated in the dried fish products. Previous studies have shown that fungal contamination of sun dried fish vary can be regional specific with Saccharomyces sp., Mucor sp., Rhodotorula sp., Schizosaccharomyce sp., Acremonium sp., Rhizopus sp., Absidia sp., Aureobasidium sp., Trichoderma sp., Cladosporium sp., Alternaria sp., and Candida sp. isolation in different regions (Olajuyigbe et al., 2014; J; ob, Agina, \& Dapiya, 2016). In addition, the uncommon fungi species Candida tropicalis, Candida stellatoidea, Microsporum audunii, Trichophyton rubrum were isolated from smoked-dried fish sold at Nigeria (Fatima, Idris, \& Gloria, 2016). In this study, we observed that filamentous fungi contamination of dried fish was more prevalent than yeast-like fungi, which may be due to its stronger reproduction and diffusion ability. Spore production in filamentous fungi make it easy to adhere and survive in high protein nutrient sources such as dried fish. The species of contaminated fungi required further molecular identification. Agarose electrophoresis results showed successful PCR amplification of 25 strains (Fig. 3).

\subsection{Genetic identification of contaminated fungi}

Amplified fungal sequences were used as BLAST queries against the 

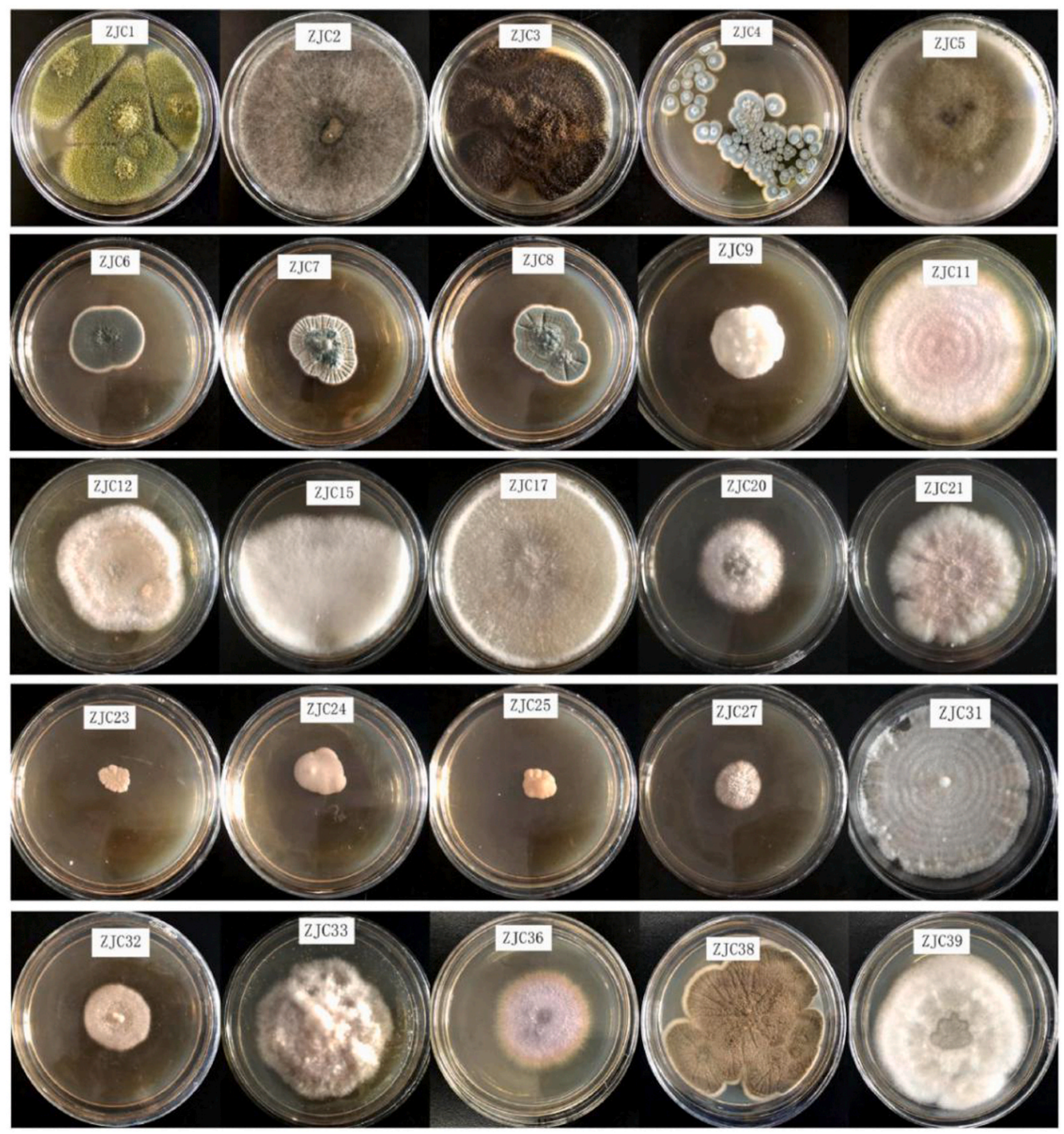

Fig. 2. Colony morphology of 25 fungal isolates from seven dried fish products sold at the Zhanjiang market, China.

NCBI database. It shows the fungi isolated from dried fish samples had 97-100\% similarity compared with closely related fungi in the GenBank. Through BLAST alignment analysis, the molecular identification results of 25 strains are shown in Fig.3.

According to genetic identification, three types of Aspergillus sp. isolated from dried fish were A. flavus, A. fumigatus and A. niger (see Table 2). A. flavus is the most common of Aspergillus fungi that has been reported to contaminate most of smoked and sun dried fish (Atef, Manal, Howayda, Rasha, \& Abdel-Dayem, 2011; Akinyemi, Adejola, Obasa, \& Ezeri, 2011; Olajuyigbe et al., 2014; Osibona, Gunyebi, \& Samuel, 2018). Aspergillus sp. can produce a large number of conidia and the high moisture promotes the germination of its spores, which increases the risk of fungal production in dried fish. In addition to the above 3 Aspergillus species, A. tamari, A. sydowii, A. versicolor,A. fumigatus,
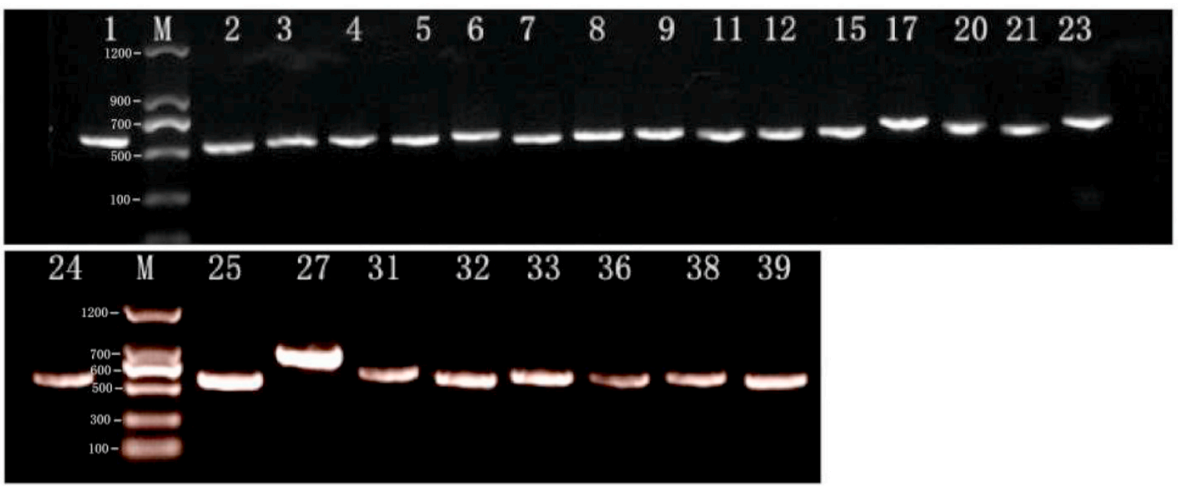

Fig. 3. PCR amplifications of rRNA gene with ITS 1 and ITS 4 primers in 25 isolates (different numbers represent different isolates, M:DNA ladder). 
A. aculeatus, A. tubingensis, A. tereus, A. ochraceus and A. wentii have also been reported in dried salted fish (Fafioye, Efuntoye, \& Osho, 2001; Adebayo-Tayo, Onilude, \& Ukpe, 2008; Osibona, Gunyebi, \& Samuel, 2018; Singapurwa et al., 2018). Aflatoxin-producing fungi isolation means the potential contamination with mycotoxins. Exposure to aflatoxins can cause chronic health disorders including hepatitis B and hepatocellular carcinoma, which seriously threaten human health (Liu, Chang, Marsh, \& Wu, 2012).

Penicillium citrinum was detected in the dried fish samples and also reported in dried fish samples sold in Giza, Eygpt (Hassan et al., 2011). Penicillium oxalicum and P. christenseniae were initially found in dried fish and this may have been due to the higher water activity and storage temperature conditions in Zhanjiang, as such conditions are most suitable for Penicillium sp. growth. Nine isolates from 7 Fusarium species were detected in samples which reflects the diversity of Fusarium contamination of dried fish products. These results are in line with those reported by Fafioye, Efuntoye, and Osho (2002) and Nyamwaka, Nyamache, \& Maingi (2017), who reported that Fusarium contamination of smoke-dried fish in Nigeria and sun dried fish in Kenya, respectively. Among the three dominant fungal genera, Trichoderma sp. and Saccharomyces sp. are the most common fungi isolated from dried fish products (Wogu \& Iyayi, 2011; Ayeloja et al., 2018). It is interesting that Rhizopus sp. and Mucor sp. are the fungal genera widely isolated from dried fish (Fafioye et al., 2002; Oku \& Amakoromo, 2013; Akwuobu et al., 2019) but we did not detect them in our samples. Ceriporia lacerata and Phellinus noxious are the rot fungi commonly present in decayed plants (Sahashi et al., 2015; Wang, Chu, Wu, Zhao, \& Xu, 2017) and basidiospores of $P$. noxious are highly pathogenic and can cause serious brown root rot disease (Hsiao, Hung, \& Sun, 2019). The isolation of two rot fungi in the dried fish samples suggest environmental contamination of dried fish by rot fungi during drying of fish on the wood. Phialemoniopsis sp. is a pathomycete widely distributed in the air, industrial water, plant material, river water, sewage, and soil (Tsang et al., 2014). It has been reported to cause serious skin and soft tissue infections in humans (Desoubeaux et al., 2014; Perdomo et al., 2013). In our study, the presence of 25 fungal isolates from dried fish samples could be due to the unclean processing environment and/or disregard to conditions of strict temperature and humidity control.

\subsection{Mycological survey}

Table 3 shows that dried fish samples sold in the market were contaminated with a range of different fungal species with total counts ranged from $1.07 \pm 0.04 \times 10^{2}-0.4 .58 \pm 1.37 \times 10^{4} \mathrm{cfu} / \mathrm{g}$. Generally, it could be assumed that the dried fish sold by different retailers would be contaminated with different fungal level. The A. flavus contamination was detected in seven types of dried fish products with relatively high values ranging from $1.10 \pm 0.06 \times 10^{3}$ to $2.40 \pm 0.32 \times 10^{4} \mathrm{cfu} / \mathrm{g}$. A. niger counts varied from $1.25 \pm 0.22 \times 10^{2}$ to $3.10 \pm 0.38 \times 10^{3} \mathrm{cfu} / \mathrm{g}$ isolated from four dried fish species while $A$. fumigatus was $7.21 \pm 1.76$ $\times 10^{2} \mathrm{cfu} / \mathrm{g}$ detected in only $S$. niphonius (Fig. 4). The total fungal counts was consistent with previous reports. Job, Agina \& Dapiya (2016) reported the $A$. flavus contamination in smoked-dried fish was $1.00 \pm 0.42$ $\times 10^{3}-9.00 \pm 3.82 \times 10^{3} \mathrm{cfu} / \mathrm{g}$. The contamination frequency of Aspergillus sp. in dried fish was $63.9 \%$, significantly higher than in dried fish sold in North-Central Nigeria open markets (28.6\%) (Akwuobu et al., 2019), but lower than in dried fish sold in Zambia (88\%) (Kachapulula, Akello, Bandyopdhyay, \& Cotty, 2018). Thus the fungal contamination significantly varied between regions and countries. Nyamwaka, Nyamache \& Maingi (2017) reported a contamination frequency $17.6 \%$ of $A$. niger, $9.5 \%$ of $A$. flavus, $10.8 \%$ of $A$. fumigatus. The species most frequently isolated from dried fish samples is A. flavus and this is an indication of its ubiquitous nature (Fafioye et al., 2002; Osibona, Gunyebi, \& Samuel, 2018). This is mostly related to the strong spore reproduction and mycelium diffusion ability of Aspergillus sp. (Wang, Dijksterhuis, Wyatt, Wösten, \& Bleichrodt, 2015). High frequency of Aspergillus sp. contamination carries a potential risk of aflatoxin production, which seriously endangers human health.

Penicillium sp. is a common contaminating genus isolated from dried fish. In this study, a high frequency of occurrence of $P$. citrinum, $P$. christenseniae and $P$. oxalicum ranging from $1.23 \pm 0.04 \times 10^{3}-4.58 \pm$ $1.37 \times 10^{4}, 2.10 \pm 1.00 \times 10^{3}-3.69 \pm 1.72 \times 10^{4}$ and $2.17 \pm 0.24 \times$

Table 2

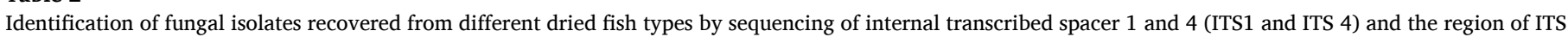
rRNA gene compared with sequences listed in the GenBank for similar species.

\begin{tabular}{|c|c|c|c|c|c|c|}
\hline \multicolumn{4}{|c|}{ Fungi isolated from dried fish } & \multicolumn{2}{|l|}{ Fungal gene bank } & \multirow[t]{3}{*}{ Similarity (\%) } \\
\hline \multirow[t]{2}{*}{ ZJC No. } & \multirow[t]{2}{*}{ Fungi } & \multicolumn{2}{|l|}{ No. Of nucleotides } & \multirow[t]{2}{*}{ Accession No. In Bank } & \multirow[t]{2}{*}{ Fungi } & \\
\hline & & With ITS1 primer & With ITS4 primer & & & \\
\hline 1 & Aspergillus flavus & 574 & 597 & MH591448.1 & Aspergillus flavus & 99 \\
\hline 2 & Neoscytalidium dimidiatum & 553 & 553 & KX464231.1 & Neoscytalidium hyalinum & 99 \\
\hline 3 & Aspergillus niger & 551 & 542 & FJ431207.1 & Aspergillus niger & 99 \\
\hline 4 & Penicillium citrinum & 545 & 538 & MG733753.1 & Penicillium citrinum & 100 \\
\hline 5 & Trichoderma harzianum & 557 & 557 & MF871551.1 & Trichoderma harzianum & 99 \\
\hline 6 & Penicillium oxalicum & 533 & 530 & MG733738.1 & Penicillium oxalicum & 97 \\
\hline 7 & Penicillium christenseniae & 577 & 576 & MK267451.1 & Penicillium expansum & 98 \\
\hline 8 & Penicillium christenseniae & 553 & 551 & MK267451.1 & Penicillium expansum & 98 \\
\hline 9 & Fusarium equiseti & 544 & 542 & MH578583.1 & Fusarium equiseti & 99 \\
\hline 11 & Fusarium oxysporum & 529 & 523 & MH879861.1 & Fusarium oxysporum & 98 \\
\hline 12 & Fusarium equiseti & 546 & 539 & MH581383.1 & Fusarium equiseti & 99 \\
\hline 15 & Phellinus noxious & 573 & 573 & HQ400698.1 & Phellinus noxious & 98 \\
\hline 17 & Ceriporia lacerata & 540 & 538 & JX623917.1 & Emmia lacerata & 99 \\
\hline 20 & Nigrospora sphaerica & 545 & 544 & MG733725.1 & Nigrospora sphaerica & 97 \\
\hline 21 & Fusarium chlamydosporum & 550 & 561 & MG250446.1 & Fusarium chlamydosporum & 98 \\
\hline 23 & Kodamaea ohmeri & 586 & 589 & KY103876.1 & Kodamaea ohmeri & 99 \\
\hline 24 & Cutaneotrichosporon mucoides & 568 & 564 & KY103029.1 & Cutaneotrichosporon arboriformis & 99 \\
\hline 25 & Naganishia diffluens & 555 & 541 & KY104326.1 & Naganishia diffluens & 99 \\
\hline 27 & Phialemoniopsis curvata & 577 & 576 & NR132076.1 & Phialemoniopsis curvata & 99 \\
\hline 31 & Fusarium incarnatum & 523 & 512 & MH290471.1 & Fusarium incarnatum & 99 \\
\hline 32 & Fusarium avenaceum & 554 & 546 & MF509747.1 & Fusarium acuminatum & 98 \\
\hline 33 & Fusarium nelsonii & 583 & 575 & GQ505434.1 & Fusarium nelsonii & 99 \\
\hline 36 & Fusarium verticillioides & 551 & 559 & JH654505.1 & Fusarium verticillioides & 99 \\
\hline 38 & Aspergillus fumigatus & 538 & 535 & AF181859.1 & Aspergillus fumigatus & 98 \\
\hline 39 & Fusarium equiseti & 513 & 510 & MH578583 & Fusarium equiseti & 98 \\
\hline
\end{tabular}


Table 3

Fungal load of dried fish products sold in the Zhanjiang market, China.

\begin{tabular}{|c|c|c|c|c|c|c|c|}
\hline \multirow[t]{2}{*}{ Fungal isolate } & \multicolumn{7}{|c|}{ Total fungal load $(\mathrm{cfu} / \mathrm{g}) /$ number of isolates $(\mathrm{n}=10)$} \\
\hline & H.maculatus & P.crocea & L.erythopterus & T. thynnus & S.niphonius & E.tetradactylum & T. lepturus \\
\hline A. flavus & $2.40 \pm 0.32 \times 10^{4}$ & $1.75 \times \pm 0.48 \times 10^{3}$ & $3.20 \pm 0.53 \times 10^{3}$ & $1.37 \pm 0.23 \times 10^{3}$ & $5.23 \pm 1.28 \times 10^{3}$ & $1.10 \pm 0.06 \times 10^{3}$ & $4.45 \pm 2.10 \times 10^{3}$ \\
\hline A. niger & $1.33 \pm 0.77 \times 10^{3}$ & $-{ }^{a}$ & $3.10 \pm 0.38 \times 10^{3}$ & $1.90 \pm 0.25 \times 10^{2}$ & - & $1.25 \pm 0.22 \times 10^{2}$ & $3.31 \pm 0.28 \times 10^{2}$ \\
\hline A. fumigatus & - & - & - & - & $7.21 \pm 1.76 \times 10^{3}$ & - & - \\
\hline P.citrinum & - & $4.58 \pm 1.37 \times 10^{4}$ & $1.85 \pm 0.55 \times 10^{3}$ & - & - & - & $1.23 \pm 0.04 \times 10^{3}$ \\
\hline P.christenseniae & - & $8.11 \pm 3.93 \times 10^{3}$ & - & $3.69 \pm 1.72 \times 10^{4}$ & $2.10 \pm 1.00 \times 10^{3}$ & - & - \\
\hline P.oxalicum & $3.67 \pm 0.11 \times 10^{3}$ & - & $2.23 \pm 0.08 \times 10^{3}$ & - & - & $2.17 \pm 0.24 \times 10^{3}$ & - \\
\hline F. equiseti & - & - & $3.19 \pm 0.47 \times 10^{2}$ & $6.32 \pm 2.91 \times 10^{3}$ & $5.53 \pm 1.08 \times 10^{2}$ & - & - \\
\hline F.oxysporum & - & - & - & $1.09 \pm 0.05 \times 10^{2}$ & - & - & $2.20 \pm 1.05 \times 10^{3}$ \\
\hline F. chlamydosporum & $2.11 \pm 0.66 \times 10^{4}$ & - & $2.10 \pm 0.74 \times 10^{2}$ & $1.02 \pm 0.45 \times 10^{3}$ & - & $3.11 \pm 1.17 \times 10^{2}$ & - \\
\hline F. incarnatum & - & $3.76 \pm 1.38 \times 10^{3}$ & - & - & $1.48 \pm 0.23 \times 10^{2}$ & - & - \\
\hline F. verticillioides & $1.66 \pm 0.28 \times 10^{2}$ & - & - & $3.74 \pm 1.02 \times 10^{3}$ & - & $1.11 \pm 0.16 \times 10^{2}$ & - \\
\hline F. nelsonii & - & - & - & - & - & $3.02 \pm 1.43 \times 10^{3}$ & - \\
\hline F.avenaceum & - & - & $1.00 \pm 0.08 \times 10^{2}$ & - & - & $3.22 \pm 0.42 \times 10^{3}$ & - \\
\hline T. harzianum & $1.23 \pm 0.06 \times 10^{3}$ & - & - & - & $4.36 \pm 1.84 \times 10^{3}$ & - & - \\
\hline K. ohmeri & $2.10 \pm 0.25 \times 10^{2}$ & - & - & - & - & - & - \\
\hline C.mucoides & - & - & & $1.24 \pm 0.14 \times 10^{2}$ & - & - & - \\
\hline N. diffluens & - & - & $1.07 \pm 0.04 \times 10^{2}$ & - & - & $1.10 \pm 0.29 \times 10^{2}$ & - \\
\hline P. curvata & - & - & - & - & $6.11 \pm 2.13 \times 10^{2}$ & - & - \\
\hline N. dimidiatum & - & - & - & $2.64 \pm 0.49 \times 10^{3}$ & $7.83 \pm 4.93 \times 10^{2}$ & - & - \\
\hline P. noxious & - & - & - & $1.53 \pm 0.22 \times 10^{2}$ & - & - & - \\
\hline C. lacerata & - & - & - & $1.10 \pm 0.25 \times 10^{2}$ & - & - & - \\
\hline N.sphaerica & - & - & $2.53 \pm 0.63 \times 10^{2}$ & - & - & - & - \\
\hline
\end{tabular}

a -:no growth.

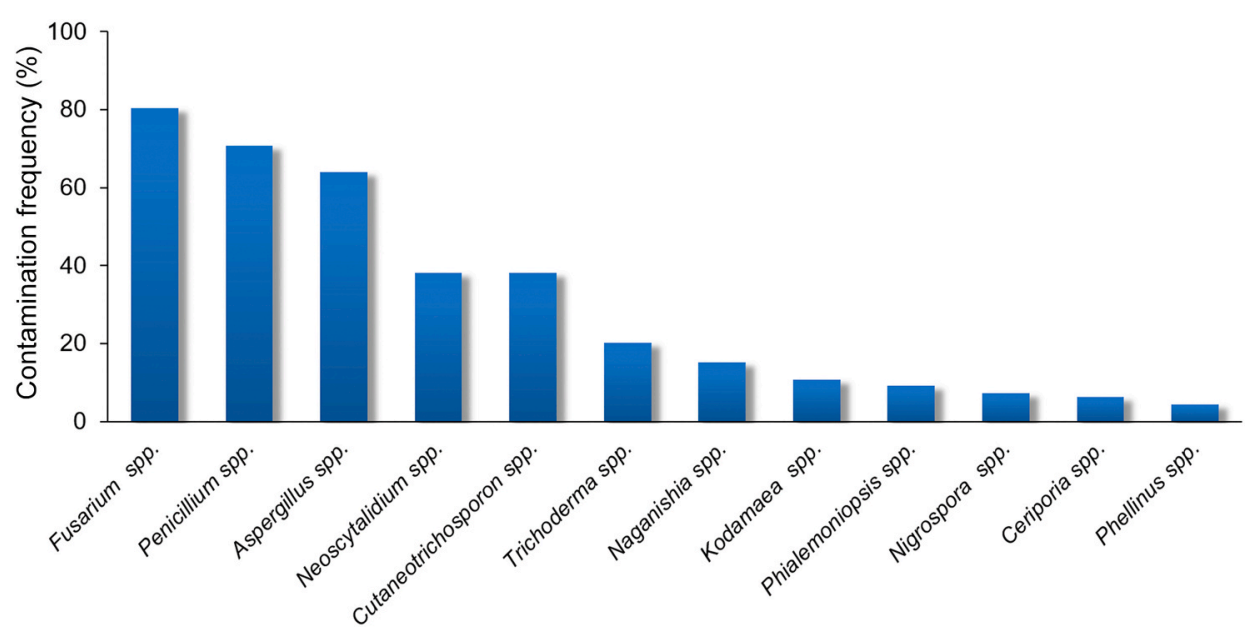

Fig. 4. Contamination frequency (\%) of different fungal species in dried fish samples.

$10^{3}-3.67 \pm 0.11 \times 10^{3} \mathrm{cfu} / \mathrm{g}$ respectively were observed. The contamination frequency of Penicillium sp. in dried fish was $70.7 \%$, which is higher than the Aspergillus sp. (Fig. 4). In many dried fish research, Penicillium sp. contamination appears inevitable (Atef et al., 2011; Wogu $\square$ Iyayi, 2011). P. citrinum, $P$. oxalicum and $P$. christenseniae, $P$. digitatum and $P$. chrysogenum have also been reported in smoked dried fish (Job, Agina, \& Dapiya, 2016; Oyebamiji \& Oyebimpe, 2013). Penicillium sp. is saprophytic fungus which mainly grows on rotten fruit, vegetables, meat and various moist organic matters. Hou, Li, and Li (2010) showed that when the humidity increases from 40 to $80 \%$, the toxin-producing ability of $P$. citreoviride is increased. Judet, Bensoussan, Perrier-Cornet, and Dantigny (2008) reported that water activity is important for sporulation and germination of Penicillium chrysogenum conidia. Production of conidia enables Penicillium sp. to proliferate and spread rapidly on food. During early stages of the drying process, when there is a high moisture content on the fish surface, it provides an ideal condition for rapid Penicillium sp. growth.

In this study, seven Fusarium sp. were isolated with total fungal counts ranging from $1.00 \pm 0.08 \times 10^{2}$ to $2.11 \pm 0.66 \times 10^{4} \mathrm{cfu} / \mathrm{g}$ in all dried fish samples. F. chlamydosporum, $F$. verticillioides and $F$. equiseti were the most frequently detected with the contamination level ranging from $2.10 \pm 0.74 \times 10^{2}$ to $2.11 \pm 0.66 \times 10^{4}, 1.11 \pm 0.16 \times 10^{2}-3.74 \pm$ $1.02 \times 10^{3}$ and $3.19 \pm 0.47 \times 10^{2}-6.32 \pm 2.91 \times 10^{3} \mathrm{cfu} / \mathrm{g}$ respectively. Although the contamination level of Fusarium sp. was lower than the Aspergillus sp., the occurrence frequency of Fusarium sp. was significantly higher than Aspergillus sp.. Fusarium contamination in dried fish means the occurrence of trichothecene mycotoxins, which is should not be neglected. The occurrence of Fusarium sp. in smoked dried fish has also been reported in other countries (Job, Agina \&;Dapiya, 2016; Fafioye, Efuntoye \&;Osho, 2002) but the contamination levels were not as high as samples from Zhanjiang market in China. That may due to the high humidity ( $>90 \%$ ) most of the year, which is ideal for the growth and reproduction of Fusarium sp., especially on a high protein medium. Detection of Fusarium sp. in dried fish implies a possibility of production of fumonisins, trichothecenes and zearalenone, all of which pose a threat to human health. These mycotoxins are more likely to be produced when dried fish is processed in an unclean environment or poor storage conditions.

In addition to the three dominant fungal genera described above, Trichoderma sp. and Kodamaea sp. are the others detected in dried fish 
(Nyamwaka, Nyamache \& Maingi, 2017). In this study, T. harzianum were isolated from dried fish with total fungal counts in ranged of 1.23 $\pm 0.06 \times 10^{3}-4.36 \pm 1.84 \times 10^{3} \mathrm{cfu} / \mathrm{g}$. K. ohmeri was isolated from only one dried fish species with $2.10 \pm 0.25 \times 10^{2} \mathrm{cfu} / \mathrm{g}$. Besides, some uncommon fungi such as $C$. mucoides $\left(1.24 \pm 0.14 \times 10^{2} \mathrm{cfu} / \mathrm{g}\right), N$. diffluens $\left(1.07 \pm 0.04 \times 10^{2}-1.10 \pm 0.29 \times 10^{2}\right)$, P. curvata $\left(6.11 \pm 2.13 \times 10^{2}\right)$, $N$. dimidiatum $\left(7.83 \pm 4.93 \times 10^{2}-2.64 \pm 0.49 \times 10^{3}\right)$, P. noxious $(1.53$ $\left.\pm 0.22 \times 10^{2}\right)$, C. lacerata $\left(1.10 \pm 0.25 \times 10^{2}\right)$ and $N$. sphaerica $(2.53 \pm$ $0.63 \times 10^{2}$ ) with relatively low contamination levels were detected in the dried fish samples. These fungi are mostly environmental contaminants. In view of seafood safety, consumption of dried fish contaminated with fungal species such as Aspergillus sp., Fusarium sp., Penicillium sp., Mucor sp., and Rhizopus sp. can cause health issues as a majority are pathogenic (Paterson \& Lima, 2017). There are many factors that influence the dried fish product safety. Firstly, unhygienic processing environment and undesirable storage conditions such as high temperature and humidity, both of which promote fungal reproduction and diffusion. Secondly, air-exposed drying operation lead to contamination of dried fish products by insects and their secreta and excreta. Thirdly, other storage condition such as oxygen concentration and illumination intensity. In addition, during processing, fishermen and workers touch the fish frequently during processing, which allow a transfer of environmental fungi from their hands to the fish surface. Also, consumers inadvertently transfer some fungi to the products when they select them by hand.

\subsection{Mycotoxin contamination in dried fish}

For optimization of the MS/MS parameters, $\mathrm{AFB}_{1}$, T-2, OTA and DON were successfully detected. MRM chromatograms of 4 the targeted mycotoxins in the standard solution are shown in Fig. 5. Four contaminating mycotoxins were detected in 12 samples of the 70 tested which amounted to $17.1 \%$ detection rate in the dried fish products. The contaminated frequency of $\mathrm{AFB}_{1}$ and OTA in all samples were higher than $\mathrm{T}-2$ and $\mathrm{DON}$. $\mathrm{AFB}_{1}$ was detected in 9 samples including 6 dried fish species products (except in the fish $T$. thynnus) with values ranging from 0.03 to $3.52 \mu \mathrm{g} / \mathrm{kg}$. The $\mathrm{AFB}_{1}$ contamination rate in dried fish products was $12.8 \%$. T-2 was detected in L. erythopterus-S3, T. thynnus-S8 and T. thynnus-S2 with values of $1.53,0.86$ and $0.21 \mu \mathrm{g} / \mathrm{kg}$, respectively. OTA was detected in five samples with values ranging from 0.03 to 2.21 $\mu \mathrm{g} / \mathrm{kg}$. DON was found only in L. erythopterus-S3 at a concentration of $0.71 \mu \mathrm{g} / \mathrm{kg}$. The $\mathrm{AFB}_{1}, \mathrm{~T}-2$, OTA and $\mathrm{DON}$ residues were detected concurrently in L. erythopterus-S3 (Table 4). The contamination rate of T2, OTA and DON in dried fish were $4.28 \%, 7.14 \%$ and $1.42 \%$, respectively.
Aflatoxin is the most ubiquitous and toxic among nearly 400 mycotoxins identified to date. There are four important aflatoxins, $\mathrm{AFB}_{1}$, $\mathrm{AFB}_{2}, \mathrm{AFG}_{1}$ and $\mathrm{AFG}_{2}$ and among these $\mathrm{AFB}_{1}$ is the most toxic (Liu et al., 2012). The European Commission has set the maximum level for $\mathrm{AFB}_{1}$ at $2-12 \mu \mathrm{g} / \mathrm{kg}$ to nuts, peanuts, corn and oils seeds (EC, 2010). Chronic exposure to high $\mathrm{AFB}_{1}$ concentrations can lead to cancer, including hepatocellular carcinoma (Ferreira et al., 2019; Matsuda et al., 2013) and hence a potential health risk to the population consuming dried fish products. Jonsyn \& Lahai (1992) identified $\mathrm{AFB}_{1}, \mathrm{AFG}_{1}$ and $\mathrm{AFG}_{2}$ in 20 samples of dried smoked fish. Sam et al. (2015) reported that A. flavus and $A$. niger isolated from dried fish sold in India by a fuming process produced $0.001-5.492 \mu \mathrm{g} / \mathrm{kg} \mathrm{AFB}_{1}$ and $0.01-2.96 \mu \mathrm{g} / \mathrm{kg} \mathrm{AFG}_{1}$, while Fagbohun \& Lawal (2015) reported that 2.73-4.03 $\mu \mathrm{g} / \mathrm{kg} \mathrm{AFB}_{1}$ and $2.01-3.53 \mu \mathrm{g} / \mathrm{kg} \mathrm{AFG}$ in smoked dried fish sold in Nigeria. Because dried fish has an extended shelf-life, it is a widely consumed and popular food especially in coastal areas because it is freely available. Hence, the regulations need to be more stringent to ensure the quality and safety of dried fish products it is necessary to establish a food safety management system to strictly control drying, storage and selling environments.

The occurrence of T-2, OTA and DON residues in dried fish products were also detected in dried fish sold in the market. Although the contamination level was relatively low, mycotoxins cannot be easily degraded without special treatment. T-2 is the most toxic type A trichothecene mycotoxin, it is an environmental contaminant. A new report shows that reproductive disruption is a key adverse effect of T-2 toxin (Yang et al., 2020). Therefore, detection of T-2 indicated the relatively high health risk of Fusarium contamination in dried fish. In this study, we detected the co-occurrence of multiple mycotoxins in dried

Table 4

Contamination levels of mycotoxins in dried fish samples $(\mu \mathrm{g} / \mathrm{kg})$.

\begin{tabular}{lllll}
\hline Sample & $\mathrm{AFB}_{1}$ & $\mathrm{~T}-2$ & OTA & DON \\
\hline H.maculatus-S4 & 0.05 & $-{ }^{\mathrm{a}}$ & - & - \\
H.maculatus-S7 & - & - & 0.24 & - \\
P. crocea-S2 & 0.09 & - & - & - \\
P. crocea-S5 & 0.04 & & & \\
L.erythopterus-S2 & $0.21^{\mathrm{a}}$ & - & 0.63 & - \\
L.erythopterus-S3 & 2.42 & 1.53 & 2.21 & 0.71 \\
T. thynnus-S6 & 0.32 & - & 0.03 & - \\
T. thynnus-S8 & 2.11 & 0.86 & - & - \\
T. thynnus-S9 & 3.52 & - & - & - \\
S. niphonius-S2 & - & 0.21 & - & - \\
S. niphonius-S2 & - & - & 0.04 & - \\
E.tetradactylum-S1 & 0.03 & - & - & - \\
\hline
\end{tabular}

${ }^{\text {a }}$ Not detected, $\mathrm{AFB}_{1}$ : aflatoxin $\mathrm{B}_{1}, \mathrm{~T}-2$ : T-2 toxin, OTA: ochratoxin $\mathrm{A}, \mathrm{DON}$ : deoxynivalenol.

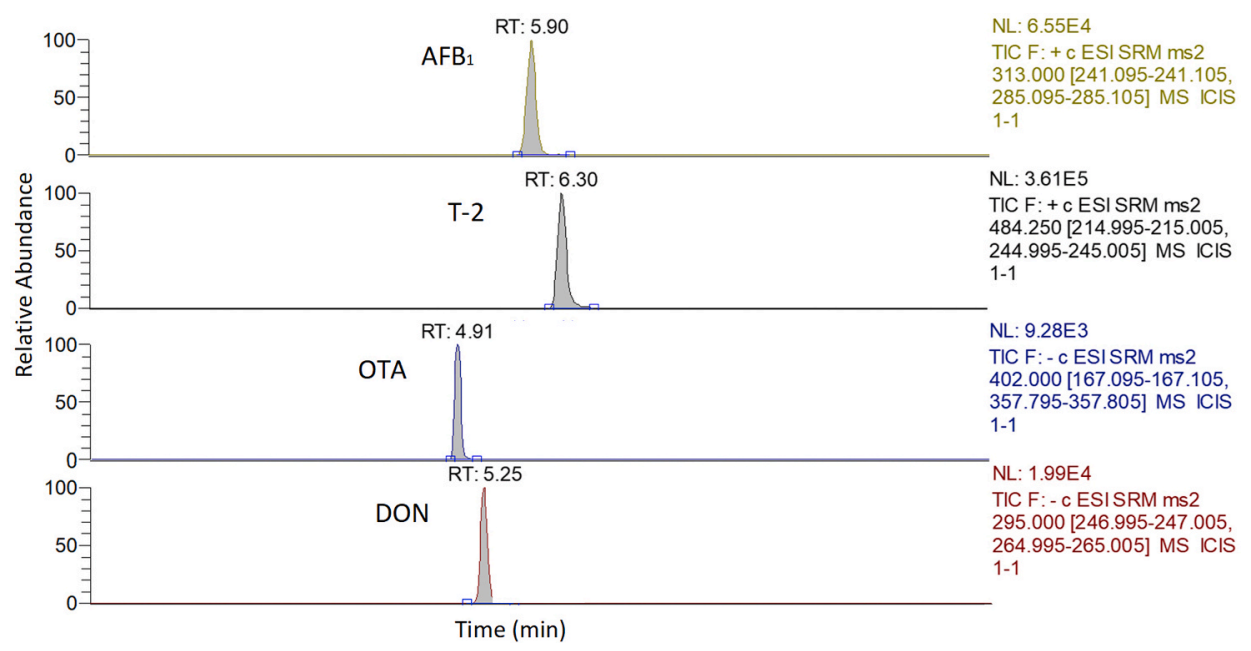

Fig. 5. LC-MS/MS MRM chromatograms of mixed standard solutions of aflatoxin $\mathrm{B}_{1}\left(\mathrm{AFB}_{1}\right)$, $\mathrm{T}-2$ toxin (T-2), ochratoxin $\mathrm{A}$ (OTA) and deoxynivalenol (DON). 
fish with up to four mycotoxins isolated from some samples. Co-occurrence of mycotoxins is due to at least three different reasons; (i) most fungi are simultaneously able to produce different mycotoxins, (ii) competition among different fungi cause them to secrete fungal toxins to resist invasion by others, and (iii) a self-protective mechanism produced by fungi to survive against adversity (low water activity and high protein) (Alassane-Kpembi et al., 2017). Low level contamination of individual mycotoxins in dried fish is quite common (e.g., $\mathrm{AFB}_{1}$, OTA and ZEN) and frequently detected (Akinyemi et al., 2011; Gonkowski et al., 2018; Sun et al., 2015). But the co-contamination of mycotoxins in food products is rare. Multi-mycotoxin studies reported foodstuff containing more than one mycotoxin could impact animal and human health at low concentrations (Alassane-Kpembi et al., 2017; Mahdjoubi et al., 2020). Since 1992, the contamination of sun/smoked dried fish products with a single or a combination of mycotoxins has been highlighted (Jonsyn \& Lahai, 1992). These findings imply potential health risk to people's health if someone consumes dried fish with multi-fungal contamination. Therefore, it is important for dried fish to be packaged and stored at low temperature, which effectively reduce the probability of air exposure, decrease water activity and inhibit microbial reproduction on dried fish.

\section{Conclusion}

This is the first investigation of fungal diversity and multi-mycotoxin contamination of the dried fish commodities sold in southern China market. It is also the first report of co-occurrence of four mycotoxins in dried fish sold in the Zhanjiang market. Results showed the presence of toxigenic fungi and mycotoxin residues in the dried fish samples. High contamination frequency of three dominant fungal genera (Fusarium, Aspergillus and Penicillium) pose a health risk due to unhygienically and poorly stored dried fish. The $\mathrm{AFB}_{1}, \mathrm{~T}-2$, OTA and DON residues detected in dried fish pose the greatest health concerns. This information will raise awareness and possible lead to guidelines on proper processing methods and the clean storage of dried seafood products, to prevent fungal growth and limit mycotoxin production.

\section{CRediT authorship contribution statement}

Yijia Deng: Conceptualization, Formal analysis, Writing - original draft, Visualization. Yaling Wang: Funding acquisition, Validation, Writing - review \& editing, Supervision. Qi Deng: Project administration, Methodology. Lijun Sun: Project administration, Formal analysis. Rundong Wang: Investigation, Writing - review \& editing. Lin Ye: Investigation, Software, Formal analysis. Sen Tao: Formal analysis. Jianmeng Liao: Project administration, Validation. Ravi Gooneratne: Writing - review \& editing, Supervision.

\section{Declaration of competing interest}

The authors would like to declare that there is no conflict of interest in this paper.

\section{Acknowledgements}

This work was supported by the National Natural Science Foundation of China (No. 31871898) and Guangdong Provincial Special Fund For Modern Agriculture Industry Technology Innovation Teams (2019KJ149, 2019KJ151) and the program for scientific research startup funds of Guangdong Ocean University (R19050).

\section{References}

Adebayo-Tayo, B. C., Onilude, A. A., \& Ukpe, G. P. (2008). Mycoflora of smoke-dried fishes sold in Uyo, Eastern Nigeria. World Journal of Agricultural Sciences, 4(3), 346-350.
Adekoya, I., Obadina, A., Phoku, J., Nwinyi, O., \& Njobeh, P. (2017). Contamination of 395 fermented foods in Nigeria with fungi. Lebensmittel-Wissenschaft und -Technologie- Food Science and Technology, 86, 76-84, 396.

Adeyeyea, S. A. O. (2016). Quality and safety assessment of sun dried meat product (kundi) from Ibadan, Oyo state, Nigeria. Cogent Food \& Agriculture., 2, Article 1209074.

Akinyemi, A. A., Adejola, A. Q., Obasa, S. O., \& Ezeri, G. (2011). Aflatoxins in smokeddried fish sold in Abeokuta, Ogun State, south-west Nigeria. In Proceedings of the Environmental Management Conference Federal University of Agriculture. Abeokuta, Nigeria (pp. 478-487).

Akwuobu, C. A., Antiev, W. S., \& Ofukwu, R. A. (2019). Fungal contaminants of smokedried fish sold in open markets in Makurdi, Benue State, North-Central Nigeria. Food and Nutrition Sciences, 290-297.

Alassane-Kpembi, I., Schatzmayr, G., Taranu, I., Marin, D., Puel, O., \& Oswald, I. P. (2017). Mycotoxins co-contamination: Methodological aspects and biological relevance of combined toxicity studies. Critical Reviews in Food Science and Nutrition, 57(16), 3489-3507.

Atapattu, R., Sama, R., \& Ajeewa, U. (1990). Fungi associated with dried fish in Sri Lanka. Mycopathologia, 111(1), 55-59.

Atef, A. H., Manal, A. H., Howayda, M., Rasha, M., \& Abdel-Dayem, R. (2011). Detection of aflatoxigenic moulds isolated from fish and their products and its public health significance. Nature and Science, 9(9), 106-114.

Ayeloja, A. A., George, F. O. A., Jimoh, W. A., Shittu, M. O., \& Abdulsalami, S. A. (2018). Microbial load on smoked fish commonly traded in Ibadan, Oyo State, Nigeria. Journal of Applied Sciences and Environmental Management, 22, 493-497.

Begum, M., Akter, T., Ahmed, A. T. A., \& Md, K. A. (2011). Evaluation of quality and storage stability of commercially produced dried fish of Tengra (Mystus vittatus) with laboratory produced dried fish products. International Journal of Bio-resource and Stress Management, 2, 246-249.

Dègnon, R. G., Atrevy, B., Adjou, E. S., Ahoussi, E., \& Soumanou, M. M. (2018). Occurrence of microbial loads in smoked fishes marketed in the Lakeside Village of Guezin (Southern Benin) and associated microbiological hazards. American Journal of Microbiological Research, 6(5), 187-190.

Desoubeaux, G., García, D., Bailly, E., Augereau, O., Bacle, G., De Muret, A., et al. (2014). Subcutaneous phaeohyphomycosis due to Phialemoniopsis ocularis successfully treated by voriconazole. Medical Mycology Case Reports, 5(1), 4-8.

EC. (2010). Commission Regulation (EU) No 165/2010 of 26 February 2010 amending Regulation (EC) No 1881/2006 setting maximum levels for certain contaminants in foodstuffs as regards aflatoxins. Office Journal of European Union L50/8.

Fafioye, O. O., Efuntoye, M. O., \& Osho, A. (2002). Studies on the fungal infestation of five traditionally smoke-dried freshwater fish in Ago-Iwoye, Nigeria. Mycopathologia, 154, 177-179.

Fagbohun, E. D., \& Lawal, O. U. (2015). Aflatoxins investigation and mycobiota of selected marketed smoked-dried fish samples in Ado-Ekiti, Nigeria and their environmental health implications. British Microbiology Research Journal, 7, 126-132.

Fatima, M. S., Idris, A. N., \& Gloria, T. (2016). Mycological evaluation of smoked-dried fish sold at Maiduguri metropolis, Nigeria: Preliminary findings and potential health implications. Applied Microbiology, 2(4), 2471-9315.

Ferreira, R. G., Cardoso, M. V., de Souza Furtado, K. M., Espíndola, K. M. M., Amorim, R. P., \& Monteiro, M. C. (2019). Epigenetic alterations caused by aflatoxin b1: A public health risk in the induction of hepatocellular carcinoma. Translational Research, 204, 51-71.

Gonkowski, S., Obremski, K., Makowska, K., \& Rytel, L. (2018). Levels of zearalenone and its metabolites in sun-dried kapenta fish and water of Lake Kariba in Zambia-A preliminary study. The Science of the Total Environment, 637, 1046-1050.

Hassan, A. A., Hassan, M. A., El Shafei, H. M., El Ahl, R. M. H. S., \& El-Dayem, R. H. A. (2011). Detection of aflatoxigenic moulds isolated from fish and their products and its public health significance. Nature and Science, 9, 106-114.

Hou, H. F., Li, Q. W., \& Li, X. M. (2010). Effect of temperautre and water activity on growth and toxin production of Penicillium citreoviride. Chinese Journal of Control of Endemic Diseases, 25, 104-106 (in Chinese).

Hsiao, W. W., Hung, T. H., \& Sun, E. J. (2019). The pathogenicity of basidiospores of Phellinus noxious which causes brown root rot disease in Taiwan. Taiwania, 64(2), 189-194.

Jeya, S. J. R., Vijayalakshmi, S. K., \& Jeyasekaran, G. (2003). Effect of delayed salting and drying on histamine and volatile amines formation in sardines (Sardinella gibbosa). SDMRI Research Publication, 3, 64-71.

Jimoh, W. A., Ayeloja, A. A., Oladele-Bukola, M. O., Muideen, A., Azeez, A. F., \& Salami, S. R. (2014). Isolation of fungi infesting smoked African Catfish from markets in Ibadan, Nigeria. Nigerian Journal of Fisheries and Aquaculture, 2(2), 13-17.

Job, M. O., Agina, S. E., \& Dapiya, H. S. (2016). Occurrence of aflatoxigenic fungi in smoke-dried fish sold in Jos Metropolis. British Microbiology Research Journal, 11(1), $1-7$.

Jonsyn, F. E., \& Lahai, G. P. (1992). Mycotoxic flora and mycotoxins in smoke - dried fish from Sierra Leone. Nahrung, 36(5), 485-489.

Judet, D., Bensoussan, M., Perrier-Cornet, J. M., \& Dantigny, P. (2008). Distributions of the growth rate of the germ tubes and germination time of Penicillium chrysogenum conidia depend on water activity. Food Microbiology, 25(7), 902-907.

Kachapulula, P. W., Akello, J., Bandyopdhyay, R., \& Cotty, P. J. (2018). Aflatoxin contamination of dried insects and fish in Zambia. Journal of Food Protection, 81(9), 1508-1518.

Kumolu-Johnson, C. A., Aladetohun, N. F., \& Dimele, P. E. (2010). The effects of smoking on the nutritional qualities and shelf-life of Clarias gariepinus (BURCHELL 1822). African Journal of Biotechnology, 9(1), 73-76. 
Liu, Y., Chang, C. H., Marsh, G. M., \& Wu, F. (2012). Population attributable risk of aflatoxin-related liver cancer: Systematic review and meta-analysis. European Journal of Cancer, 48, 2125-2136.

Mahdjoubi, C. K., Arroyo-Manzanares, N., Hamini-Kadar, N., García-Campaña, A. M., Mebrouk, K., \& Gámiz-Gracia, L. (2020). Multi-mycotoxin occurrence and exposure assessment approach in foodstuffs from Algeria. Toxins, 12(3), 194.

Matsuda, Y., Wakai, T., Kubota, M., Osawa, M., Sanpei, A., \& Fujimaki, S. (2013). Mycotoxins are conventional and novel risk biomarkers for hepatocellular carcinoma. World Journal of Gastroenterology, 17, 2587-2590.

Nyamwaka, I. S., Nyamache, A. K., \& Maingi, J. M. (2017). Microfungi Associated with sun dried rastrineobola argentea sold in Gucha south district in Kenya. Microbiology Research Journal International, 19(3), 1-8.

Oku, I., \& Amakoromo, E. R. (2013). Microflora of fresh and smoke-dried fish in Yenagoa metropolis, Nigeria. African Journal of Microbiology Research, 7(35), 4451-4456.

Olajuyigbe, O., Akande, G. R., Ezekiel, C. N., et al. (2014). Aflatoxigenic moulds and aflatoxin contamination of retailed fishery products in Lagos markets. Mycotoxicology, 1, 57-63.

Oluwaniyi, O. O., \& Dosumu, O. O. (2009). Preliminary Studies on the effect of processing methods on the quality of three commonly consumed marine fishes in Nigeria. Biokemistri, 21(1), 1-7.

Omotayo, O. P., Omotayo, A. O., Mwanza, M., \& Babalola, O. O. (2019). Prevalence of mycotoxins and their consequences on human health. Toxicology Research, 35(1), $1-7$.

Osibona, A. O., Gunyebi, O. O., \& Samuel, T. O. (2018). Storage fungi and mycotoxins associated with stored smoked Catfish (Clarias gariepinus). Journal of Applied Sciences \& Environmental Management, 22, 643-646.

Oyebamiji, F., \& Oyebimpe, F. (2013). Microbial identification of smoke-dried fish (Clarias gariepinus) from some local markets in Ibadan metropolis. Wudpecker Journal of Agriculture Research, 2(11), 294-298.

Paterson, R. R. M., \& Lima, N. (2017). Filamentous fungal human pathogens from food emphasising Aspergillus, Fusarium and Mucor. Microorganisms, 5(3), 44.

Perdomo, H., García, D., Gené Cano, J. J., Sutton, D. A., Summerbell, R., \& Guarro, J. (2013). Phialemoniopsis, a new genus of Sordariomycetes, and new species of Phialemoniumand Lecythophora. Mycologia, 105, 398-421.

Sa'adatu, A. J., Nura, S., \& Muhammad, A. (2019). Assessment of mycological quality of smoked African catfish (Clarias gariepinus) sold at Sabon-gari market, Kano Nigeria. Annals of Microbiology and Infectious Diseases, 1(2), 13-18.

Sahashi, N., Akiba, M., Ota, Y., Masuya, H., Hattori, T., Mukai, A., et al. (2015). Brown root rot caused by Phellinus noxious in the Ogasawara (Bonin) islands, southern
Japan - current status of the disease and its host plants. Australasian Plant Disease Notes, 10(1), 1-5.

Sam, J. F., Jeyasanta, I. K., \& Edward, P. J. K. (2015). Aflatoxins investigation on dried fishes of Tuticorin, south east coast of India. Journal of Foodborne Zoon Disease, 3, 49-62.

Singapurwa, N. M. A. S., Suprapta, D. N., Gunam, I. B. W., \& Khalimi, K. (2018). Identification of contaminant fungi on Pedetan, an dry fish product of Lemuru (Sardinella lemuru). Journal of Biology, Agriculture and Healthcare, 8, 75-82.

Sugumar, G., Jawahar, A. T., \& Jayachandran, P. (1995). Sanitation in fish curing yards of Tuticorin. Tamil Nadu. Fishery Technology, 32(2), 136-138.

Sun, W. S., Han, Z., Aetts, J., Nie, D. X., Jin, M. T., Shi, W., et al. (2015). A reliable liquid chromatography-tandem mass spectrometry method for simultaneous determination of multiple mycotoxins in fresh fish and dried seafoods. Journal of Chromatography A, $1387,42-48$.

Tolosa, J., Barba, F. J., Font, G., \& Ferrer, E. (2019). Mycotoxin incidence in some fish products: QuEChERS methodology and liquid chromatography linear ion trap tandem mass spectrometry approach. Molecules, 24(3), 527.

Tsang, C. C., Chan, J. F., Ip, P. P., Ngan, A. H., Chen, J. H., Lau, S. K., et al. (2014). Subcutaneous phaeohyphomycotic nodule due to Phialemoniopsis hongkongensis sp. nov. Journal of Clinical Microbiology, 52(9), 3280-3289.

Wang, N., Chu, Y. L., Wu, F. A., Zhao, Z. L., \& Xu, X. Y. (2017). Decolorization and degradation of Congo red by a newly isolated white rot fungus, Ceriporia lacerata, from decayed mulberry branches. International Biodeterioration \& Biodegradation, $117,234-244$.

Wang, F. F., Dijksterhuis, J., Wyatt, T., Wösten, H. A. B., \& Bleichrodt, R. (2015). VeA of Aspergillus Niger increases spore dispersing capacity by impacting conidiophore architecture. Antonie van Leeuwenhoek, 107, 187-199.

Wogu, M. D., \& Iyayi, A. D. (2011). Mycoflora of some smoked fish varieties in Benin City Nigeria, Ethiopian. Ethiopian Journal of Environmental Studies and Management, 4, 36-38.

Yang, X., Liu, P., Cui, Y., Xiao, B., Liu, M., Song, M., et al. (2020). Review of the reproductive toxicity of T-2 toxin. Journal of Agricultural and Food Chemistry, 68, 727-734.

Zachariasova, M., Dzuman, Z., Veprikova, Z., Hajkova, K., Jiru, M., Vaclavikova, M., et al. (2014). Occurrence of multiple mycotoxins in European feedingstuffs, assessment of dietary intake by farm animals. Animal Feed Science and Technology, 193, 124-140. 